\title{
Analysis on the Development Path of Heilongjiang Pop Music Industry
}

\author{
Qi Lili \\ Heihe College, Heilongjiang, China 164300
}

Keywords: New media, pop music industry, symbiosis and co prosperity, development and innovation

\begin{abstract}
The development of the pop music industry is closely related to the mass media. In the new media era, the spread of Heilongjiang pop music industry, sales model and development direction have undergone tremendous changes. This paper attempts to analyze and study the characteristics of new media communication, the interactive relationship between new media and pop music industry, the symbiosis and prosperity of digital technology, the integration of new media technology and pop music industry, and the impact on the development of pop music industry. It is hoped that this paper can explore a way for the development of Heilongjiang pop music industry at present and in the future.
\end{abstract}

\section{Introduction}

The emergence of new media, represented by the Internet and mobile media, has changed the traditional pop music industry dramatically. With the advent of pirated CD-ROMs and free downloads on the Internet, the emergence of new media has not only dealt an almost devastating blow to the pop music industry, but also pointed out a bright path for the declining pop music record companies.Both McLuhan and Bozmann point out that the emergence of each important new medium creates new discourse symbols, and at the same time changes our discourse structure. The replacement of mass media technology has brought about cultural changes, especially the emergence of new media has made tremendous changes in popular culture. As an important part of pop culture, the development of pop music industry is closely related to the spread of new media.

\section{Pop Music Changed the Direction of Popular Music Development}

What is new media? A more comprehensive explanation is that the whole process of collecting, processing, processing, transporting and displaying information content by means of computer, modern digital communication and network switching is constituted and applied to the mass communication industry. The social organizations engaged in this industry are called new media. New media communication tools mainly include: Internet, MAN, LAN and wireless network with digital carrier of satellite communications; receiving and receiving terminal tools mainly include computers, mobile phones, newspaper reading screens, digital television and so on. The main characteristics of new media communication are: no time difference, no borders, fast transmission 
of text pictures; large amount of information; interactive live broadcast; multimedia live and short messages, MMS, animation, blogs, podcasts and other flexible means of communication.

Digital technology is the basis of new media, and digital technology just opened the digital era of pop music. The beginning of the real pop music industry is to start with the birth of digital music. According to the transitional development of communication technology, the relationship between modern pop music industry and new media should be from the emergence of CD media to the digital beginning of pop music industry, followed by the flourishing network media and the emergence of online music, followed by the emergence of the fifth media mobile phone and production Born of wireless music -- the future direction of the pop music industry.

"CD is the earliest manifestation of digital technology in the music industry, CD brings not only high-quality audio, digital clarity, but also changes people's listening habits to pop music, people can choose their favorite play at any time, you can also edit any combination, which in the past are all It's hard to do. " So digital technology really opens the door to the pop music industry. But in recent years, the demand for CDs has been declining, and sales have been declining. With the advent of the Internet, more and more music lovers use MP3 format to save music. Downloading or listening to CDs from the Internet has become the first choice for many people.

Network media, as one of the most prosperous new media, has been gradually approaching the mainstream media, and the network media based on computer technology is precisely the best representative of the new media. The product of the combination of the pop music industry and the Internet is online music, also known as online music, online music sales in the CD piracy rampant, network free download prevailing in this environment has to take a road of development. In the mainland of Heilongjiang, record companies own the copyright of pop music and can serve as content providers (CP) to provide pop music products to specialized music sales websites or telecom operators (SP), while service providers mainly inherit the music products provided by content providers and sell them to users through network platforms. The emergence of network media has also greatly changed the pattern of the music industry. Compared with the pattern of the traditional pop music industry, the network not only breaks the profit chain of the legitimate sales on which record companies used to rely, but also makes the network operators become one of the competitors who get a share.

As the latest new media, mobile media has been named the fifth media as soon as it appeared, which shows the degree of attention. As a new media and the integration of pop music industry, mobile phone media mainly embodies the function of downloading ringtones and playing songs. This is also inseparable from the development of wireless networks, with the manufacturing and operation technology maturing, mobile phone functions are constantly improving. Wireless music downloads and color ringtones have become the two most successful collaborations between mobile media and the pop music industry.

Before the advent of wireless music, the revenue streams of traditional record companies were mainly record sales, commercial performances and the survival of artists'brokers. But because of the squeeze of pirated CD-ROMs and the Internet, the record industry was shrinking until the two butterflies ringtones were in full swing. In 2003, China Mobile first put forward the concept of value-added color ring tone, which was soon popular with mobile phone users. Since then, Heilongjiang Unicom and Heilongjiang Telecom have opened this business one after another.

In 2004, Heilongjiang's record industry earned only 200 million yuan in official record revenue, and the record company received 1.67 billion yuan in copyright revenue after the five-fifth dividend between content providers (record companies) and SP (wireless value-added service providers). It is precisely because mobile communication services have strict protection of copyright, which is of great significance to the development of pop music industry. 
Mobile media platform has a great influence on popularizing pop music. The theme song of Beijing Olympic Games, Me and You, was launched through Heilongjiang Mobile Wireless Music Platform within one hour after the opening ceremony. The number of downloads reached 5.73 million in 26 hours, breaking through the Seoul Olympic theme song "Hand in Hand" in nine years. The world releases 5 million albums. It can be seen that the new media will greatly promote the pop music industry in Heilongjiang.

At present, the domestic wireless music industry chain has been initially formed, which plays an important role in the pop music industry. The value chain is divided into several levels: content providers (mainly record companies), service providers (SPs) and telecommunications operators (China Mobile and Unicom). China Mobile occupies 80\% of Heilongjiang's wireless music market share, and its hegemony can not be shaken. Actually, cooperating with the record company is a kind of helplessness to a greater extent. The purpose of China Mobile to set up the central music platform is to set up a huge digital music library through its own channels and become the largest digital music distributor in Heilongjiang and even the world. Once the model is mature, the strong operators will lose the bargaining power of the record company. Power. At present, many record companies have more than half of their revenue from wireless music, so the more they rely on operators, once operators adjust the revenue sharing model, the harder it will be for record companies.

\section{Expanding the Scope of Popular Music}

In the traditional media era, the spread of pop music must rely on radio or television and other media, but these media are of a certain regional nature, which makes pop music can only be limited to a small range. But with the development of new media, such as the Internet, information is truly shared globally, so pop music has become more international and influential, rather than distinctive geographical features. Pop music has become extremely fast in the form of digital music with the help of new media.

Another advantage brought by the new media is the interpersonal communication at any time and anywhere. Interpersonal communication in the network is very effective. Because of the interactive characteristics of new media, both the interaction between pop music producers and consumers and the interaction between consumers are frequent. This advantage is incomparable with traditional media. With timely feedback and communication, the pop music industry will be closer to the public and develop better.

\section{Pop Music Affects the Consumption Behavior of Audiences.}

The emergence of network music reflects the consumer's pursuit of personalized characteristics, through the independent choice of download behavior, people do not need to listen to radio, television hosts nagging, not limited by the broadcast time, you can choose your favorite music anytime and anywhere. Anyone with a computer can surf the Internet and enjoy the convenience and rapidity of the new technology.

But along with the convenience of downloading comes free downloading, a piracy infringement that has hit the pop music industry. What's worse, free downloads have caused legitimate operators to cut the price of their music products and even offer free downloads on new modes of transmission to ensure the number of listeners, in addition to reducing sales of genuine music. This trend toward free music has led to a new value for pop music: the recognition of the value of music and the use of various channels to listen to it, but the lack of a price scale to measure it, or even the gradual default of its price to zero. Globally, the total number of legal music downloads reached 775 million in mid-2006, up 89\% from the same period in 2005. The number of music that provides 
official downloading services on the Internet is close to 4 million. When fans downloaded digital music free of charge from the Internet, the default payment for the music product is zero. Is this the spirit of sharing advocated by digital networks? Of course not, the pop music industry has come to an end when people think the value of musical products is zero. Therefore, the emergence of new media is not only an opportunity but also a challenge to the development of pop music industry.

\section{Pop Music Changed the Sales Mode of the Pop Music Industry}

Before the advent of digital music, people appreciated music products mainly by purchasing various specific storage media through broadcasting devices. When music products were digitized, computers became a comprehensive device for playing, acquiring and storing music. Network storage made it possible to provide mass music content. In the digital age, the medium of music carrier has changed from the object of record to the digital audio file of computer. The commodity form of pop music has changed from tangible to intangible, and the commodity of music has also changed from material wealth to information wealth. Nowadays, pop music commodities are invisible, do not need specific material carriers at all, and more convenient to share and exchange. Music products stored as a music format are generally stored in the database, not occupying physical space, so that the cost of goods is reduced, is conducive to reducing the price of music products.

Previously, the purchase of music products need to go to the sales channel to buy in person, and after the emergence of new media, especially the network and mobile phone media to provide a variety of means to consume digital music products, so that information access, sales are more rapid. Online music sales and wireless music sales are slowly becoming the two main value chains of the pop music industry.

The industry chain of traditional music industry, from creation to final audience consumption, has gone through the creation, production, publicity and marketing links, each link can be profitable, but the biggest subversion caused by digital music is that each link can not be profitable.

Today, with the prosperity and development of new media, the traditional operation channels of pop music industry have been seriously damaged. In the past, the main source of profit for record companies was the sales of products. Record companies copied music onto CDs and sold it to audio companies. Consumers bought physical CDs in the audio-visual market. In the new media era, the industrial manufacturing links in the pop music industry chain have disappeared, music products have been sold directly on the Internet, and the distributors, wholesalers and retailers of traditional products have been eliminated. At the same time, the former manufacturers of audio equipment have merged with the manufacturers of new media equipment such as computer equipment and network equipment

\section{Continuous Innovation is the Foundation of the Symbiotic}

This requires strong user resources and user stickiness. Today Heilongjiang's major portal websites are beginning to show signs of this, such as Sina Music Gallery's free audio-visual and advertising profitable business model. The slogans of "One-Stop Service", "Massive, Genuine, Free" which Sina Music Gallery launched in early 2007 are quite attractive. In fact, this model is similar to Baidu and Baidai's advertising for copyright cooperation model, Sina created a model of advertising for copyright. Users can listen to authorized songs for free, and then divide them into advertisements with record companies. These new models need to regulate the Internet copyright protection regulations, crack down on illegal and free downloads on the Internet, and strengthen cooperation between record companies and music websites in order to achieve a win-win situation.In addition to the mobile web pages of major portals, Heilongjiang Mobile and Unicom are 
the biggest platforms for wireless music sales. Heilongjiang Mobile launched the whole song downloading business in October 2007 to advance the layout for the 3G era. After less than two years of operation, China Mobile's central music platform has completely changed the original pattern of Heilongjiang digital music. Unicom also launched its own whole song downloading business in 2007 and vigorously promoted the "10155 music portal". Heilongjiang Telecom's "love music" music platform was launched in November 8, 2007. Since then, several major operators in Heilongjiang have participated in the music platform business, preparing for the $3 \mathrm{G}$ era.

\section{Conclusions}

At present, the development of this relatively slow in China, in addition to the color ring tone business, there is no more advanced channel to produce, but also shows that the prospects of the domestic huge. Overseas, online sales of pop music products dominate, with Apple's ITUNES Music Store, which began in 2003, selling 1 million pieces of music in its first week. In Heilongjiang, the development of this field is still full of obstacles.After the major record companies dock with the media, the rich content of the communication platform will gradually be guaranteed, but the record companies also need to gradually adapt to the market, produce more content to cater to consumer tastes, and need pop music to produce diversified products. The new media has given the public a more diverse way of expression, given ordinary people the opportunity to become famous, and also contributed to the popularization of grass-roots culture, which provides a new media era of pop music with more rich material, open up a diversified market.

\section{Acknowledgments}

Topic: Research on the operation path of Heilongjiang pop music industrialization

Source: Heilongjiang provincial social science research and planning project

Issue number: 18YSE619

\section{References}

[1] The Internet revenue structure of Heilongjiang music industry in Chinalabs:2004.

[2] Yang Jiameng and Cai Zhijian: An Analysis of the Development Ideas of Heilongjiang Digital Music Industry, Contemporary Economy, 2008 (1).

[3] AI Consulting Group: 2007 Heilongjiang online music Brief Edition report. 